\title{
PENGARUH MORDAN TAWAS DAN CUKA TERHADAP HASIL PEWARNAAN ECO PRINT BAHAN KATUN MENGGUNAKAN DAUN JATI (Tectona Grandis)
}

\author{
Fitri Masyitoh $^{1^{*}}$, Ernawati $^{2 *}$ \\ Program Studi Pendidikan Kesejahteraan Keluarga, Jurusan Ilmu Kesejahteraan Keluarga \\ Fakultas Pariwisata dan Perhotelan \\ Universitas Negeri Padang \\ Jl. Prof. Dr. Hamta, Air Tawar Padang, Kel. Air Tawar Barat, Kec. Padang Utara, Kota Padang, Kode Pos 25171 \\ Sumatera Barat. Indonesia \\ Email: fitrimasyitoh26@gmail.com
}

\begin{abstract}
Abstrak
Penelitian ini dilatar belakangi sebagai upaya pemanfaatan pewarna alam daun jati untuk membuat motif tekstil dengan teknik pewarnaan eco print yang ramah lingkungan. Penelitian ini bertujuan untuk mendeskripsikan nama warna (Hue), gelap terang (Value) dan kejelasan bentuk yang dihasilkan dari pewarnaan eco print bahan katun menggunakan daun jati (Tectona grandis) dengan mordan tawas dan cuka. Jenis penelitian ini merupakan penelitian eksperimen. Jenis data berupa data primer.pewarnaan eco print dengan mordan tawas menghasilkan nama warna Pomdadour Purple, warna kurang terang dan kejelasan bentuk termasuk kategori sangat jelas. Pada pewarnaan eco print dengan mordan cuka menghasilkan nama warna Muddy Waters Brown, warna terang dan kejelasan bentuk termasuk kategori cukup jelas.
\end{abstract}

Kata Kunci: eco print, daun jati, mordan.

\begin{abstract}
This research is motivated as an effort to use natural teak leaf dyes to make textile motifs with eco-friendly coloring techniques. This study aims to describe the color name (Hue), dark darkness (Value) and the clarity of the shape resulting from the staining of eco print cotton using teak leaves (Tectona grandis) with mordan alum and vinegar. This type of research is experimental research. The type of data in the form of primary data. Eco print staining with mordan alum produces the color name Pomdadour Purple, the color is not bright and the clarity of the shape, including the category is very clear. On eco print staining with mordan vinegar produces Muddy Waters Brown color name, bright color and shape clarity including the category is quite clear..
\end{abstract}

Keywords: ecoprint, teak leaves, mordant.

\section{PENDAHULUAN}

Teknik yang digunakan untuk mengolah kain kebanyakan masih menggunakan zat warna sintetis yang dapat mencemari lingkungan. Menurut Paryanto (2012:26) "Penggunaan zat pewarna sintetis yang memang terbukti lebih mudah berdampak negatif yaitu bersifat kastinogenik (menyebabkan kanker) akibat kandungan berat pada pewarna sintetik. Unsur logam berat pada pewarnaan sintetis seperti krom, tembaga dan seng juga menyebabkan penyakit seperti kanker kulit dan kerusakan otak pada manusia". Untuk ituperlu menggali zat warna alternatif yang lebih aman seperti pewarnaan menggunakan bahan alam yang mudah terdegredasi dan ramah lingkungan yang berupa tanaman. Tidak hanya menjadi pewarna, namun daun dari tanaman yang mengandung pewarna juga bisa dimanfaatkan kandungan warnanya dan tulang daunnya serta permukaan daunnya untuk menjadi motif yang disebut eco print.

Eco print adalah proses mencetak warna dan bentuk ke bahan tekstil melalui kontak langsung. Menurut Irianingsih (2018:7) “eco print adalah memindahkan pola (bentuk) dedaunan dan bunga-bunga ke atas permukaan berbagai kain yang sudah diolah untuk menghilangkan lapisan lilin dan kotoran halus pada kain agar warna tumbuhan mudah menyerap (teknik mordan)". Proses eco print menggunakan teknik gulung (Bundles) dikerjakan dengan cara penempelan bahan alam secara langsung pada bahan tekstil kemudian pengukusan untuk memunculkan bentuk dan warna dari bahan alam.

Salah satu pewarnaan tekstil teknik ecoprint yang dapat dijadikan zat warna alam adalah tanaman jati. 


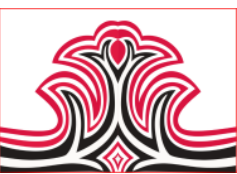

Nama ilmiah jati adalah Tectona grandis. Menurut Kembaren dkk (2013:314) "pemanfaatan kandungan senyawa antosianain pada daun jati akan menghasilkan pewarna alami yang aman bagi kesehatan maupun lingkungan".

Bahan tekstil yang digunakan untuk pewarnaan eco print sebaiknya yang berasal dari alam. Menurut Ernawati Dkk (2008: 156) "Serat sellulosa terbagi menjadi serat biji, serat batang, serat daun, dan serat buah". Selanjutnya menurut Sulistiami (2013:29) "kain katun merupakan salah satu jenis kain yang berasal dari serat solulosa atau tumbuh-tumbuhan".Pada kesempatan ini penulis memilih bahan katun sebagai objek penelitian karena bahan katun salah satu bahan yang bagus dalam penyerapan zat warna.

Dalam proses eco print diperlukan juga pengerjaan moerdanting. Menurut Irianingsih (2018:10) "Sebelum digunakan, kain harus diolah dulu yang disebut mordan (mordanting). Gunanya adalah untuk meluruhkan lapisan lilin atau pemutih yang melekat pada permukaan kain supaya warna-warna tetumbuhan mudah diserap". Selain proses mordanting dalam eco print juga terdapat proses fiksasi. Menurut Lestari (2002:8) "Fiksasi merupakan proses untuk memperkuat zat warna alam warna agar tidak luntur". Setiap proses mordan maupun fiksasi berpengaruh pada hasil akhir. Penggunaan mordan maupun fiksasi yang berbeda akan menghasilkan warna yang beragam. Peneliti menggunakan mordan dan fikasi yang sama yaitu tawas dan cuka.

Berdasarkan hasil pra-eksperimen yang dilakukan peneliti yang dihasilkan dari pewarnaan eco print bahan katun menggunakan daun jati (Tectona grandis) dengan mordan tawas warna yang dihasilkan ungu kemerahan, sedangkan dengan mordan cuka menghasilkan warna orange kemerahan. Pada penelitian ini peneliti akan melihat nama warna, gelap terang warna dan kejelasan bentuk. Penulis tertarik untuk melakukan penelitian dengan judul "Pengaruh mordan tawas dan cuka terhadap hasil pewarnaan eco print bahan katun menggunakan daun jati (Tectona grandis)".

\section{KAJIAN TEORI}

Pewarnaan tekstil dilakukan dengan proses eco print. Menurut Flint (2008:21) eco print diartikan sebagai proses mencetak warna dan bentuk ke kain melalui kontak langsung. Selanjutnya menurut Husna (2016:285) "Flint mengaplikasikan teknik ini dilakukan dengan cara menempelkan tanaman yang
Gorga Jurnal Seni Rupa

Volume 08 Nomor 02 Juli-Desember 2019 p-ISSN: 2301-5942 | e-ISSN: 2580-2380

memiliki pigmen warna pada kain berserat alami yang kemudian direbus atau dikukus dalam kuali besar".

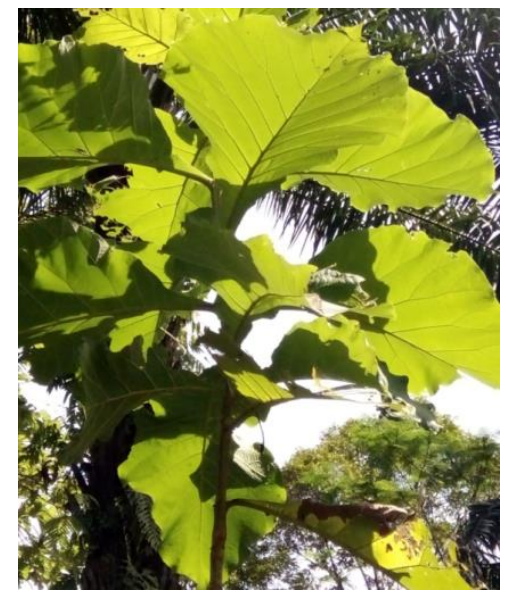

Gambar 1. Tanaman Jat (Sumber: Fitri Masyitoh, 2019)

Jati adalah sejenis tanaman dengan pohon yang tingginya mencapai $15-20 \mathrm{~m}$ yang banyak dijumpai di beberapa negara termasuk Indonesia.Jati juga dikenal sebagai tanaman penghasil kayu yang memiliki kualitas dan nilai jual yang sangat tinggi. Bentuk fisik keseluruhan dari jati merupakan pohon besar dengan batang yang bulat lurus, daun yang lebar serta memiliki bunga dan buah. Menurut Puspitarum (2013:7) "Daun jati mengandung karotenoid yang berperan penting dalam pewarnaan". Selanjutnya menurut Kembaren (2013:313) "Pemanfaatan kandungan senyawa antosianin pada daun jati akan menghasilkan pewarna alami yang aman bagi kesehatan maupun lingkungan”.

Dalam pewarnaan eco print juga dibutuhkan zat mordan. Mordan adalah zat khusus yang dapat meningkatkan lekatnya warna dan bentuk pada kain. Menurut Susanto (1980:71) "Mordan merupakan suatu zat yang dipergunakan dalam proses pencelupan agar warna yang terserap ke dalam kain lebih kuat dan dapat dipergunakan sebelum atau sesudah proses pencelupan kain”. Salah satu mordan yang dapat digunakan untuk pewarnaan eco print adalah tawas dan cuka.

Menurut Noor (2007:2) "Bahan tekstil yang diwarnai dengan zat warna alam adalah bahan-bahan yang berasal dari serat alam contohnya sutera, wol dan katun (kapas)". Berdasarkan karkteristik dan sifat-sifat katun maka penulis memilih bahan katun. Peneliti memakai bahan katun untuk pewarnaan eco print menggunakan daun jati (Tectona grandis) dengan mordan tawas dan cuka. 


\section{METODE PENELITIAN}

Jenis penelitian yang dilakukan adalah penelitian eksperimen. Menurut Sukardi (2003:179) "Penelitian eksperimen pada prinsipnya dapat didefinisikan sebagai metode sistematis guna membangun hubungan yang mengandung fenomena sebab akibat (Causaleffect relatioship).Objek dalam penelitian ini adalah bahan katun yang diwarnai dengan teknik pewarnaan eco print menggunakan daun jati (Tectona grandis) dengan menggunakan mordan tawas dan cuka.

Dalam penelitian ini, zat warna yang digunakan adalah daun jati (Tectona grandis) dengan perlakuan yang sama baik dari bahan, alat dan waktu. Perbedaannya terletak pada mordan yaitu menggunakan tawas dan cuka.

Instrumen penelitian ini adalah hasil pewarnaan eco print bahan katun menggunakan daun jati (Tectona grandis) dengan zat mordan berbeda disertai kuesioner atau angket sebagai panduan pengamatan. Kuesioner yang digunakan dalam penelitian ini adalah jenis kuesioner langsung yang tertutup sehingga responden hanya tinggal memberi tanda pada salah satu jawaban yang dianggap benar. Penelitian ini disusun menurut skala bertingkat (Rating scale) yaitu perbedaan warna (Hue), gelap terang warna (Value), dan kejelasan bentuk.

Dalam penelitian ini penulis menggunakan panelis perseorangan terbatas sebanyak 3 orang staf Pengajar Jurusan IKK FPP UNP, terdiri dari 2 orang dosen pengajar mata kuliah tekstil dan 1 orang dosen Jurusan IKK yang memiliki perhatian dan minat terhadap pewarnaan eco print, dan panelis terlatih sebanyak 15 orang mahasiswa Prodi PKK (S1 Tata Busana) dengan kriteria mempunyai kemampuan membedakan warna atau tidak buta warna, serta memahami kuesioner yang disebarkan peneliti.

Data yang terkumpul diolah diberi nilai dan disusun dalam bentuk tabel, kemudian dianalisa dengan menggunakan persentase untuk menentukan warna yang dihasilkan oleh zat warna alami daun jati (Tectona grandis) dengan mordan tawas dan cuka menggunakan uji Friedman K-Related Sample. Untuk melihat perbedaan hasil pewarnaan terhadap Hue, Value dan kejelasan bentuk yang dihasilkan pada pewarnaan eco print menggunakan ekstrak daun jati (Tectona grandis) dengan menggunakan mordan tawas dan cuka, pengolahan data menggunakan program SPSS (Statistical Product and Service Solutions) versi 16.0.

\section{HASIL DAN PEMBAHASAN}

\section{Hasil}

Uji friedman k-related sample merupakan statistik non parametik, uji ini dilakukan karena sampel kurang dari 30. Hasil data penelitian gelap terang warna (Value) terhadap 18 panelis, diperoleh nilai mean sebagai berikut: mordan tawas mendapat rata-rata 1,50 dan mordan cuka mendapat rata-rata 3,17 .

Tabel 1. Hasil Uji Friedman K-Related Sample Gelap Terang Warna (Value) yang Dihasilkan pada Pewarnaan Eco Print Bahan Katun Menggunakan Daun Jati (Tectona Grandis) dengan Mordan Tawas dan Cuka.

\section{Test Statistics ${ }^{\mathbf{a}}$}

\begin{tabular}{|l|r|}
\hline N & 18 \\
Chi-Square & 14.222 \\
Df & 1 \\
Asymp. & .000 \\
Sig. & \\
\hline
\end{tabular}

a. Friedman Test

Pada tabel 1 diatas dapat dijelaskan bahwa uji Friedman K-Related Sample gelap terang warna (Value) pada pewarnaan eco print bahan katun menggunakan daun jati (Tectona grandis) dengan mordan tawas dan cuka diperoleh nilai signifinkan senilai 0,000 yang lebih kecil dari taraf signifiknasi 0,05 atau $0,000<0,05$. Artinya bahwa terdapat perbedaan yang signifikan akibat penggunaan mordan tawas dan cuka terhadap gelap terang warna (Value) dalam pewarnaan eco print bahan katun menggunakan daun jati (Tecctona grandis).

Hasil data penelitian kejelasan bentuk terhadap 18 panelis, diperoleh nilai mean sebagai berikut: mordan tawas mendapat rata-rata 3,56 dan mordan cuka mendapat rata-rata 2,22.

Tabel 2. Hasil Uji Friedman K-Related Sample Kejelasan Bentuk yang Dihasilkan pada Pewarnaan Eco Print Bahan Katun Menggunakan Daun Jati (Tectona Grandis) dengan Mordan Tawas dan Cuka.

\section{Test Statistics ${ }^{\mathbf{a}}$}

\begin{tabular}{|l|r|}
\hline $\mathrm{N}$ & 18 \\
Chi-Square & 13.235 \\
Df & 1 \\
Asymp. Sig. & .000 \\
\hline
\end{tabular}

a. Friedman Test 


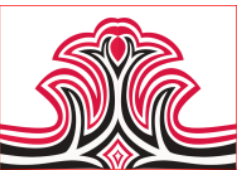

Pada tabel 2 di atas dapat dijelaskan bahwa uji Friedman K-Related Sample kejelasan bentuk yang dihasilkan pada pewarnaan eco print bahan katun menggunakan daun jati (Tectona grandis) dengan mordan tawas dan cuka diperoleh nilai signifikansi sebesar 0,000 yang lebih kecil dari taraf signifikansi 0,05 atau $0,000<0,05$. Artinya bahwa terdapat perbedaan yang signifikan akibat penggunaan mordan tawas dan cuka terhadap kejelasan bentuk dalam pewarnaan eco print menggunakan daun jati (Tectona grandis).

\section{Pembahasan}

Pewarnaan eco print dari perbedaan mordan tawas dan cuka menggunakan daun jati (Tectona grandis) terhadap hasil pewarnaan eco print bahan katun dilihat dari nama warna (Hue), gelap terang warna (Value) dan kejelasan bentuk.

Nama warna (Hue) yang dihasilkan dari perbedaan mordan terhadap hasil pewarnaan eco print bahan katun menggunakan daun jati (Tectona grandis) dapat dilihat pada tabel berikut:

Tebel 3. Nama Warna (HUE) yang Dihasilkan dari Perbedaan Mordan terhadap Hasil Pewarnaan Eco Print Bahan Katun Menggunakan Daun Jati (Tectona Grandis).

\begin{tabular}{|c|c|c|c|c|}
\hline $\begin{array}{l}\text { Eco } \\
\text { print }\end{array}$ & Wama & $\begin{array}{l}\text { Nama } \\
\text { warna }\end{array}$ & RGB & $\begin{array}{l}\text { Kode } \\
\text { Warna }\end{array}$ \\
\hline Tawas & & $\begin{array}{c}\text { Pompadour } \\
\text { Puple }\end{array}$ & $\begin{array}{l}\text { R } 125 \\
\text { G } 048 \\
\text { B } 072 \\
\end{array}$ & $\# 7 D 33048$ \\
\hline Cuka & & $\begin{array}{l}\text { Mudaty } \\
\text { Waters } \\
\text { Brown }\end{array}$ & $\begin{array}{l}\text { R } 195 \\
\text { G } 108 \\
\text { B } 100 \\
\end{array}$ & $\# \mathrm{C} 36 \mathrm{C} 64$ \\
\hline
\end{tabular}

Berdasarkan tabel 3 dapat dijelaskan nama warna beserta kode warna RGB (Red, Green dan Blue) yang memiliki nilai terendah 0 dan tertinggi 255. Dari hasil penelitian dijelaskan pada pewarnaan eco print bahan katun menggunakan daun jati (Tectona grandis) dengan mordan tawas menghasilkan nama warna (Hue) Pompadour Purple dengankode warna \#7D33048, memiliki nilai R (Red) 125 atau 49,01\%, G (Green) 048 atau $18,82 \%$ dan B (Blue) 072 atau $28,23 \%$.

Pada pewarnaan eco print bahan katun menggunakan daun jati (Tectona grandis) dengan mordan cuka menghasilkan nama warna (Hue) Muddy Waters Brown dengan kode warna \#C36C64 yang memiliki nilai R (Red) 195 atau 76,47\%, G (Green) 108 atau 42,35\% dan B (Blue) 100 atau 39,21\%.

Daun jati (Tectona grandis) merupakan salah satu tanaman yang mengandung Tanin dan Antosianin. Dalam pewarnaan tanin dapat dimanfaatkan sebagai
Gorga Jurnal Seni Rupa

Volume 08 Nomor 02 Juli-Desember 2019 p-ISSN: 2301-5942 | e-ISSN: 2580-2380

bahan pewarna dan perekat zat warna pada kain.Selain tanin daun jati juga mengandung antosianin. Menurut Ervira (2013:2) "Antosianin merupakan pigmen yang larut dalam air memberikan warna biru, ungu, kuning, violet, magenta, merah dan orange”. Berdasarkan penjelasan diatas maka dapat diambil kesimpulan bahwa daun jati (Tectona grandis) mengandung antosianin yang merupakan pembentuk warna pada tanaman dan tanin merupakan pigmen penimbul warna yang digunakan sebagai pewarnaan tekstil serta warna yang dihasilkan juga dipengaruhi oleh mordan maupun fiksasi. Hal ini sesuai dengan hasil penelitian (Handayani dan Mualimin. 2013) bahwa zat pengikat atau fiksasi dapat mempengaruhi kenampakan warna yang dihasilkan.

Berdasarkan hasil pewarnaan eco print bahan katun menggunakan daun jati (Tectona grandis) dengan mordan tawas $65,56 \%$ panelis menyatakan kurang terang. Selanjutnya hasil pewarnaan eco print bahan katun menggunakan daun jati (Tectona grandis) dengan mordan cuka $72,22 \%$ panelis menyatakan terang.Berdasarkan hasil pewarnaan eco print bahan katun menggunakan daun jati (Tectona grandis) dengan mordan tawas $66,67 \%$ panelis menyatakan sangat jelas dan pewarnaan eco print bahan katun menggunakan daun jati (Tectona grandis) dengan mordan cuka $72,22 \%$ panelis menyatakan cukup jelas.Dari hasil eksperimen yang dilakukan dan analisa data dapat diketahui bahwa hasil gelap terang warna (Value) dipengaruhi oleh mordan. Sejalan dengan hasil penelitian Husna (2016:183) "Penambahan mordan bisa digunakan supaya warna menjadi lebih terang atau gelap.... penambahan tawas, misalnya, dapat meningkatkan warna pada kain menjadi lebih tua". Selanjutnya menurut Irianingsih (2018:22) "cuka biang membuat warna cenderung lebih cemerlang”.

Berdasarkan analisis yang diperoleh dari uji Friedman K-Related Sample untuk gelap terang warna (Value) data yang diperoleh dari pewarnaan eco print bahan katun menggunakan daun jati (Tectona grandis) dengan mordan tawas dan cuka adalah 0,000 yang lebih kecil dari taraf signifikansi sebesar 0,05 atau 0,000< 0,05 artinya $\mathrm{H}_{\mathrm{o}}$ ditolak. Dari penjelasan tersebut dapat diambil kesimpulan bahwa terdapat perbedaan yang signifikan terhadap gelap terang warna (Value) pada pewarnaan eco print bahan katun menggunakan daun jati (Tectona grandis) dengan mordan tawas dan cuka.

Berdasarkan analisis yang diperoleh dari uji Friedman K-Related Sample untuk kejelasan bentuk data yang diperoleh dari pewarnaan eco print bahan katun menggunakan daun jati (Tectona grandis) dengan 
mordan tawas dan cuka adalah 0,000 yang lebih kecil dari taraf signifikansi sebesar 0,05 atau 0,000 $<0.05$ artinya $\mathrm{H}_{\mathrm{o}}$ ditolak. Dari penjelasan tersebut dapat diambil keputusan bahwa terdapat perbedaan yang signifikan terhadap kejelasan bentuk pada pewarnaan eco print bahan katun menggunakan daun jati (Tectona grandis) dengan mordan tawas dan cuka.

\section{KESIMPULA DAN SARAN 1.Kesimpulan}

Nama warna (Hue) pada pewarnaan eco print bahan katun menggunakan daun jati (Tectona grandis) dengan mordan tawas menghasilkan nama warna Pompadour Purple dengan kode warna \#7D33048 dan pada pewarnaan eco print bahan katun menggunakan daun jati (Tectona grandis) dengan mordan cuka menghasilkan nama warna Muddy Waters Brown dengan kode warna \#C36C64.

Berdasarkan hasil pewarnaan eco print bahan katun menggunakan daun jati (Tectona grandis) dengan mordan tawas $55,56 \%$ panelis menyatakan kurang terang dan pewarnaan eco print bahan katun menggunakan daun jati (Tectona grandis) dengan mordan cuka $72,22 \%$ panelis menyatakan terang.

Berdasarkan hasil pewarnaan eco print bahan katun menggunakan daun jati (Tectona grandis) dengan mordan tawas $66,67 \%$ panelis menyatakan sangat jelas dan pewarnaan eco print bahan katun menggunakan daun jati (Tectona grandis) dengan mordan cuka $72,22 \%$ menyatakan cukup jelas.

\section{Saran}

Hasil penelitian ini diharapkan dapat menambah referensi bagi Jurusan Ilmu Kesejahteraan Keluarga tentang pewarnaan eco print.

Hasil penelitian ini dapat menjadi bahan pertimbangan dalam mata kuliah tekstil untuk menggunakan pewarnaan eco print sebagai pewarnaan dan motif tekstil yang alami.

Perlu dilakukan penelitian lebih lanjut tentang bahan mordan yang lain sehingga dapat diperoleh hasil pewarnaan eco print yang bervariasi dan tentang pemanfaatan bahan alam yang lain sebagai pembuatan pewarnaan eco print.

\section{DAFTAR RUJUKAN}

Ervira, Desty. (2013). The Miracle Of Fruits. Jakarta: Agro Media Pustaka.
Flint, India. (2008). Eco Colour. Australia: Murdoch Books.

Husna, Farisah. (2016). Eksplorasi Teknik Eco Dyeing Dengan Tanaman Sebagai Pewarna Alam. e-Proceeding of Art \& Design, (Online), Vol. 3, No. 2,

(https://openlibrary.telkomuniversity.ac.id /pustaka/files/116095/jurnal_eproc/eksplo rasi-teknik-eco-dyeing-denganmemanfaatkan-tanaman-sebagai-pewarnaalam-untuk-produk-lifestyle.pdf, diakses 10 Apr. 19)

Irianingsih, Nining. (2018). Yuk Membuat Eco Print Motif Kain Dari Daun dan Bunga. Jakarta: PT Gramedia Pustaka Utama.

Kemberen, R.br., dkk. (2014). Ekstrasi dan Karakterisasi Serbuk Nano Pigmen dari Daun Tanaman jati (Tectona grandis linn. F). J. Kimia Kemasan (Online), Vol 36, No 1 , (https://media.neliti.com/media/publicatio ns/106283-ID-ekstraksi-dan-karakterisasiserbuk-nano.pdf, diakses 10 april 2019)

Lestari Kun WF. (2002). Promosi Dagang, Industri, dan Investasi Melalui Workshop Pewarnaan Batik Kria Tekstil (Tekstil Kerajinan Tenun)

Fitriana, Noor. (2007). Teknik Eksplorasi Zat Pewarna Alam Dari Tanaman Di Sekitar Kita Untuk Pencelupan Bahan Tekstil. Jurusan Pkk Ft Uny. 1-8

Handayani, P.A. dan A. Amar Mualimin. 2013. Pewrana Alami Batik Dari Tanaman Nila (Indigofera) dengan Katalis Asam. Jurnal Bahan Alam Terbuka. Vol 2 No 1:1-6

Paryanto, A. P., Kwartiningsih, E., \& Mastuti, E. (2012). Pembuatan Zat Warna Alami dalam Bentu Serbuk untuk Mendukung Industri Batik Indonesia. Jurnal Rekayasa Proses,6(1)

Puspitarum, D. L., \& Yulianto, A. (2013). Aplikasi Ekstrak Daun Jati (Tectona grandis) Sebagai Film Kaca NonPermanen. Unnes Physics Journal, 2(1)

Sulistiami dan Fathonah, Nur. 2013. "Penggunaan Penguat Jenis Mordan dan Daun Jambu Terhadap Hasil Pewarnaan Teknik Ikat Celup Pada Kain Katun”. IX (16):28s

Susanto, Sewan (1973). Seni Kerajinan Batik Indonesia, BPKB, Yogyakarta.

Sukardi. (2003). Metodologi Penelitian Pendidikan. Jakarta: PT Bumi Aksara. 